\title{
Network Evolutionary Game-Based Diffusion Mechanism regarding the Nonperformance of Farmers in Agricultural Supply Chain Finance
}

\author{
Xiaoli Li $\mathbb{B D}^{1,2}$ and Yanming Sun ${ }^{1}$ \\ ${ }^{1}$ School of Management, Guangzhou University, Guangzhou 510006, China \\ ${ }^{2}$ School of Management, Zhongkai University of Agriculture and Engineering, Guangzhou 510225, China \\ Correspondence should be addressed to Xiaoli Li; lixiaoli1949@163.com
}

Received 20 September 2021; Revised 26 December 2021; Accepted 27 January 2022; Published 28 February 2022

Academic Editor: Abdelalim Elsadany

Copyright (C) 2022 Xiaoli Li and Yanming Sun. This is an open access article distributed under the Creative Commons Attribution License, which permits unrestricted use, distribution, and reproduction in any medium, provided the original work is properly cited.

Agricultural supply chain finance effectively alleviates the problem of farmers' credit constraints and realizes the commercialization and sustainability of agriculture. However, the rapid spread of farmers' credit default behavior will seriously affect the stability of the agricultural supply chain and the wide application of agricultural supply chain finance. To prevent the rapid spread of farmers' credit default behavior, the diffusion mechanism of farmers' default behavior is studied with network evolutionary game. The results indicate the following: (a) When some farmers choose the default strategy because their default income is greater than their performance income, the default behavior in the small-world network will not spread to the whole network. However, in the scale-free network, when the default rate of return exceeds a certain threshold, it will lead to the spread of default behavior throughout the network. (b) In the small-world network, the spread of default will be inhibited to some extent with the increase of extra returns. However, the effect of raising extra returns on the spread of default behavior is not obvious in the scale-free network.

\section{Introduction}

Agriculture is an important basic industry in developing countries. Since 2004, "No. 1 Document" has focused on "agriculture, rural areas, and farmers" for 17 years in China. However, on the one hand, due to the long cycle of agricultural production and the large input of production materials in the early stage, farmers always experience a great pressure about obtaining funds during the production stage. On the other hand, the lack of collateral often makes it difficult for farmers to obtain bank loans through traditional means [1]. If the shortage of funds of farmers is not resolved, it will affect the supply of agricultural products and even the stability of the supply chain. Therefore, providing inclusive finance is a key element to maintain the stability of agricultural production [2]. The emergence of agricultural supply chain finance effectively alleviates the problem of farmers' credit constraints and simultaneously realizes the commercialization and sustainability of agriculture [3]. However, since the extensive information asymmetry and vulnerability to natural disasters, the moral hazard of farmers is prominent in the agricultural supply chain. That is, the possibility of a subjective breach of contract is greater under the influence of some factors [4]. Then, the wide application of agricultural supply chain finance will be affected. For example, the nonperforming loan ratio of the Dalian Rural Commercial Bank exceeded $8 \%$ at the end of 2018. One of the important factors is that the bank's agricultural loan ratio is significant [5]. Anyway, scholars have made some efforts to solve the information asymmetry of agricultural supply chain. For example, advanced information technologies such as sensors and Internet of Things (IoT) are used to develop smart agriculture, which has developed to Agriculture 4.0 [6-8]. But the use of these technologies is still in its infancy. Moreover, the use of new technologies cannot completely eliminate information 
asymmetry and agricultural supply chain risks. There are still unnatural events such as network crashes, hacking attacks, and natural disasters such as COVID-19 and earthquakes $[9,10]$. These factors will cause different degrees of default risks in agricultural supply chain [11]. Therefore, the urgent and important issue explored in this paper is the diffusion mechanism regarding the nonperformance of farmers in agricultural supply chain finance.

In recent several decades, the default behavior in supply chain finance has received increasing attention from academia and practitioners. Firstly, plenty of research has assessed the credit risk of supply chain finance by using either empirical or qualitative method. In other words, they tried to answer how serious the risk is. Secondly, the management and control of risk in supply chain finance are studied with game theory or text mining. Meanwhile, most of them only focus on the simple cooperative relationship among the main bodies in supply chain finance, such as the relationship between suppliers, banks, manufacturers, etc. The complex network relationship in supply chain finance is not emphasized. However, some scholars believe that there is not only a simple cooperative relationship between several subjects in supply chain finance, but also a complex relationship relying on a supply chain network. For example, Song believes that the current supply chain finance gradually evolves from a supply chain orientation to a network ecology orientation $[12,13]$. The default behavior of agricultural supply chain finance is studied from the perspective of complex network in this paper. Moreover, the influence of complex network structure on default behavior is considered as well. Thirdly, the analysis of the default risk contagion process of supply chain finance is based on complex networks and infectious disease models. But in this process, the participants are often in a passive accepting state. On the contrary, the diffusion process of default behavior is studied with evolutionary game and complex network in this paper. In this way, the subjective initiative of participants is considered.

This paper makes three contributions to the existing literature. First, differing from the existing literature focusing on assessing and predicting the risk of supply chain finance by using neural networks, analytic hierarchy processes, and gray and machine learning, this paper analyzes the diffusion process of farmers' default behavior based on a network evolutionary game, which focuses on farmers' active learning behavior in complex networks. Second, the influence of various factors on farmers' default behavior under a small world and scalefree network structure is compared. Specifically, the effect of an increase in punishment intensity and extra returns on farmers' default behavior is studied under different network structures. Third, the results show that the default behavior in the small-world network will not spread to the whole network when some farmers choose the default strategy because their default income is greater than their performance income. However, in the scalefree network, when the default rate of return exceeds a certain threshold, it will lead to the spread of default behavior throughout the network.
The remainder of this paper is organized as follows: Section 2 presents the related literature. Section 3 formulates the diffusion model of farmers' default behavior under agricultural supply chain finance. Section 4 provides a discussion of the influence of different networks, punishments, and extra returns on the diffusion process of farmers' default behavior. Finally, conclusions and managerial insights are provided in Section 5.

\section{Literature Review}

To promote the development of supply chain finance and provide financial services to a greater number of SMEs, the question of how to reduce the default risk of supply chain finance has been widely discussed in many papers. This paper contributes to the literature in the following aspects: (1) the relationship of participants in supply chain finance, (2) default behavior in supply chain finance, and (3) network evolutionary game theory and its applications.

2.1. Relationship of Participants in Supply Chain Finance. Yan et al. studied the optimal guarantee mechanism of banks, retailers, and suppliers in supply chain finance with the Stackelberg game method [14]. Yan et al. analyzed the effect of risk aversion on the cooperative strategies of banks, manufacturers, and retailers in supply chain finance [15]. In the agricultural supply chain, Yi et al. found that the intermediary platform served as a guarantor to help the farmer access bank loans, which can significantly improve the welfare of the farmer and the total profit of the supply chain [16]. Jin and Luo discussed the effect of the insurer's loading factor and the bank's risk aversion on the optimal inventory strategy in supply chain finance by using a newsvendor financing model [17]. The above studies only focus on the simple cooperative relationship among the main bodies in supply chain finance, such as the relationship between suppliers, banks, manufacturers, etc. The complex network relationship in supply chain finance is not emphasized. Moreover, Song believes that the current supply chain finance gradually evolves from a supply chain orientation to a network ecology orientation $[12,13]$. They explore the network embeddedness of different enterprises in supply chain finance and how this embeddedness difference affects the financing performance of SMEs $[18,19]$. Fayyaz et al. predicted credit risk by analyzing the network attributes of cooperative subjects in the supply chain finance network [20]. Steven and Rogers studied the impact of network power and cohesion on a firm's financial performance in supply chain finance [21].

2.2. The Default Behavior in Supply Chain Finance. The research on default behavior in supply chain finance mainly focuses on the evaluation and control of credit risk and moral hazards. In terms of risk assessment, Zhang et al. used the support vector machine and neural network method to construct the credit risk assessment system of SMEs in supply chain finance to improve the accuracy of banks' prediction of SMEs' default behaviors [22]. Wu and Liao 
developed a credit risk assessment model by using a utilitybased hybrid fuzzy axiomatic design approach [23]. Zhu et al. predicted the credit risk of SMEs in supply chain finance by a machine learning method [24-26]. Lyu and Zhao built a risk assessment model of supply chain finance by analytic hierarchy process gray assessment theory [27]. Based on a neural network, Cai et al. combined the financing risk factors for supply chain finance and built a risk assessment system [28]. Liu et al. used fractal theory to assess the financing risk of supply chain finance [29]. Liu and Huang proposed a credit risk assessment model of supply chain finance based on a support vector machine [30]. Liu and Yan evaluated the credit risk of farmers by using the fuzzy analytic hierarchy process (FAHP) [31]. Wang et al. predicted the credit risks of SMEs in supply chain finance with a multiview learning method [32]. Wu et al. explored risk assessment methods by using a genetic algorithm (GA) and backpropagation neural network (BPNN) to reduce credit risks of agricultural supply chain finance [33]. Yang et al. identified the key factors influencing the credit risk of SMEs in sustainable supply chain finance by constructing a lasso-logistic model [34]. For risk management and control, Ying et al. concluded that supply chain relationship management and asset and cash flow supervision are the key elements of the risk management of supply chain finance by mining the existing risk assessment reports of supply chain finance [35]. Peng demonstrated the possibility of agricultural supply chain financial moral hazard amplification with the sequential game method and proposed corresponding countermeasures [36]. Jin et al. reduced the default risk faced by banks by introducing a revenue sharing two-way option contract [37].

\subsection{Network Evolutionary Game Theory and Its Applications.} As an important means to study the relationship between subjects and their interaction, complex network theory has been widely used in product innovation, supply chain risk management, and other fields [38-42]. For example, Basole and Bellamy demonstrated that there is a connection between supply network structure and risk diffusion [39]. Wang et al. measured the complexity of the supply chain network structure with the disruption of risk, which can support the structural design of the supply chain [40]. In the field of supply chain finance, complex networks have also been applied to a certain extent. Based on the scale-free network and infectious disease model, Zhao et al. studied the credit risk transmission process of supply chain finance and analyzed the impact of the financing interest rate and network structure on the risk transmission process [43]. Fayyaz et al. took social network attributes into account in the credit risk prediction process of supply chain finance, which effectively improved the prediction accuracy [20].

In general, scholars have made meaningful explorations of the evaluation and management of supply chain finance default risk and default behavior from different perspectives and have achieved fruitful results. Firstly, many scholars believe that there is not only a simple cooperative relationship between several subjects in supply chain finance, but also a complex relationship relying on a supply chain network. Secondly, on the one hand, the previous research focuses on using neural networks, analytic hierarchy process gray, and machine learning to assess the credit risk of supply chain finance. On the other hand, the management and control of risk in supply chain finance is studied with game theory and text mining. However, the complex network relationship among participants in supply chain finance is considered rarely. From the perspective of complex network, the influence of different network structures on the diffusion process of breach behaviors is considered in this paper. Thirdly, the analysis of the default risk contagion process of supply chain finance is based on complex networks and infectious disease models. In this process, the participants are often in a passive accepting state. On the contrary, the diffusion process of default behavior is studied with evolutionary game and complex network in this paper. In this way, the subjective initiative of participants is considered.

\section{Diffusion Model of Farmers' Default Behavior under Agricultural Supply Chain Finance}

Under the mode of agricultural supply chain finance, production is usually organized in the ways of "company + farmer," "company + cooperative organization + farmer," etc. At the same time, farmers can apply for a certain amount of loans from banks and other financing institutions to solve the financing problem by using the real trade relationship and the credit guarantee of core enterprises. On the other hand, capital providers (such as banks) and core enterprises form control advantages by relying on their network positions to avoid default risks [13]. In addition, as agricultural producers and operators, farmers and cooperative organizations constitute the basic network layer in the financial network of the agricultural supply chain [44]. They are the main demanders of funds, as well as the source and control object of default risk. Due to information asymmetry and network relationships based on interpersonal communication and business contacts [18], once affected by the market or natural disasters, the production network layer comprised of farmers will produce a large number of credit defaults. That is, the butterfly effect of "frightening and flying together" may occur. This network relationship shows that there is a close relationship among a few farmers and an indirect relationship among the majority of farmers. That is, the connections are formed through several connections and thus have the characteristics of small-world networks. However, if some farmers with a certain influence (such as village cadres, etc.) take the lead in default, other debtors may follow. A sheep-flock effect of default risk will occur [4]. This kind of network often shows that a few nodes have a large number of connections, while most nodes have a small number of connections, which conforms to the characteristics of a scale-free network. Therefore, the analysis in this paper is based on small-world and scale-free networks.

\subsection{Diffusion Network of Farmers' Default Behavior under} Agricultural Supply Chain Finance. First, a diffusion network of farmers' default behavior $G(V, E)$ is built under 
agricultural supply chain finance, where $V$ is the collection of all nodes in the network and represents all farmers in the network. $E$ is the set of all edges in the network. If there is a connection between $i$ and $j$, it is represented by $e_{i j}=1$. This indicates that there are interpersonal communication and capital or business relationships between farmers. If there is no connection edge between $i$ and $j$, there is no direct relationship, which is represented by $e_{i j}=0$. Then, diffusion networks of farmers' default behavior under agricultural supply chain finance with scale-free and small-world characteristics are generated.

Given an initial network with a certain number of nodes, newly joined farmers connect with existing nodes according to Formula (1) to generate a scale-free farmer default behavior diffusion network $G_{1}$ under agricultural supply chain finance [45].

$$
p\left(k_{i}\right)=\frac{k_{i}}{\sum_{j} k_{j}} .
$$

Given an initial network with a certain number of nodes, each node is connected to the left and right adjacent nodes. Each existing edge of the network is randomly reconnected with a certain probability (excluding reconnection and selfloop) to generate a small-world diffusion network $G_{2}$ of farmers' default behavior under agricultural supply chain finance.

Network structure, game model, and evolution rule are three important factors of complex network evolutionary game theory. Based on a small-world and scale-free network, a game model of farmers' strategic choice will be established to study the diffusion mechanism of farmers' default behavior under agricultural supply chain finance.

3.2. Evolutionary Game Model. Farmer groups in the network under agricultural supply chain finance are divided into two homogeneous subgroups, namely, farmer Group 1 and farmer Group 2. Each farmer in the group has two strategies: default and performance. Default means that farmers do not repay loans. The strategy of performance is that farmers repay loans on time. Generally, due to the complex and changeable economic environment, it is difficult for farmers to master all the information. Therefore, they may fulfill their obligations or default and optimize their income through constant trial, imitation, and learning strategies of other subjects. That is, due to information asymmetry, they are all bounded rational individuals.

The typical model of agricultural supply chain finance, accounts receivable financing, is studied in this paper. Individual farmers are selected randomly from the above two groups to play the game, namely, farmer 1 and farmer 2 . It is assumed that the default probability of farmer 1 is $x$. The performance probability is $1-x$. Similarly, the default probability of farmer 2 is $y$, and the performance probability is $1-y$. See Table 1 for specific symbol descriptions.

Based on the above assumptions, the following game payment matrix can be constructed (see Table 2).
3.3. The Evolutionary Rules of the Diffusion of Farmers' Default Behavior. In each round of the game, each node plays a game with all its neighbors and accumulates the benefits. At the same time, the stochastic strategy evolution is carried out according to Fermi rules [45]. Namely, in this round of the game, if one's own gain is lower than the neighbor's gain, in the next round of the game, the neighbor's strategy of this round will be imitated with a certain probability. The imitation probability is calculated as follows:

$$
p\left(s_{i} \leftarrow s_{j}\right)=\frac{1}{1+e^{\left(U_{i}-U_{j}\right) / \varepsilon}}
$$

where $s_{i}$ is the strategy adopted by node $i$ at the current stage. $U_{i}$ represents node $i$ 's current cumulative gain through the game.

(2) is the evolution rule of node $i$. That is, when the cumulative benefit of node $i$ is less than that of its neighbor node $j$, node $i$ will choose the strategy of node $j$ with a large probability. In contrast, if the cumulative benefit of node $i$ is greater than that of its neighbor node $j$, it will choose to retain the original strategy with a large probability or change the original strategy with a small probability. $\xi$ is the irrational factor, that is, the uncertainty of nodes when adjusting their strategies. $\xi \longrightarrow 0$ indicates that the node rationally and definitively adjusts its strategy. $\xi \longrightarrow \infty$ indicates that the node is irrational and that the adjustment of its strategy is random.

After strategy learning, farmers will reconnect with a random probability $\gamma_{i j}$.

$$
\gamma_{i j}=\sum_{i \in G} \frac{U_{j}^{\alpha}}{U_{i}^{\alpha}},
$$

where $U_{i}$ is the revenue of node $i . \alpha$ is the preference tendency. The larger the $\alpha$ is, the more obvious the preference tendency is.

In conclusion, the evolutionary game steps of farmers' default behavior diffusion under agricultural supply chain finance are shown in Table 3.

3.4. Simulations. Based on the small-world and scale-free network, Jingdong's "Jingnongdai" will be taken as an example to study the impact of default yield, additional income, and punishment on the diffusion process of farmers' default behavior.

3.4.1. Background of the Case. The operation mode of Jingnongdai is the "agricultural value chain $+\mathrm{e}$-commerce platform." Relying on the real transactions of the value chain and the big data of platform transactions, it provides financial services for relevant customers in the supply chain together with financial institutions. For example, Renshou Jingnongdai was launched by JD in cooperation with the Sichuan Renshou Furenyuan Agricultural Development Company. Farmers can obtain loan guarantees from Renshou Company when they sign a purchase order and apply for loans from JD through purchase orders to buy 
TABle 1: Notation description.

\begin{tabular}{|c|c|}
\hline Symbol & Implication \\
\hline$R$ & The amount of accounts receivable of farmers. \\
\hline$\alpha$ & The pledge rate of accounts receivable, $0<\alpha<1$ \\
\hline A & $\begin{array}{l}\text { Additional benefits obtained from long-term cooperation with the core enterprise in the supply chain and opportunities for bank } \\
\text { refinancing when farmers repay on time. }\end{array}$ \\
\hline$r$ & Lending rate, $0<r<1$ \\
\hline$\beta$ & The yield rate brought by the normal operation of farmers after obtaining bank loans, $0<\beta<1$. \\
\hline$\beta_{1}, \beta_{2}$ & $\begin{array}{c}\text { The yield rate obtained by farmer } 1 \text { and farmer } 2 \text { when they choose the default strategy. At this time, farmers may use the bank } \\
\text { loans for other purposes (such as investment in high-risk projects) or normal operation, but they will choose not to repay } \\
\text { ultimately, } 0<\beta_{1}, \beta_{2}<1 .\end{array}$ \\
\hline$M$ & $\begin{array}{l}\text { The punishment that farmers suffer when they choose the default strategy. Such as the loss of long-term cooperation with core } \\
\text { enterprises due to breach of trust, as well as the low cost of credit obtained in the agricultural supply chain finance model. }\end{array}$ \\
\hline
\end{tabular}

TABle 2: Game payoff matrix between farmer 1 and farmer 2.

\begin{tabular}{|c|c|c|}
\hline \multirow{2}{*}{ Farmer 1} & \multicolumn{2}{|c|}{ Farmer 2} \\
\hline & Default $(y)$ & Performance $(1-y)$ \\
\hline $\begin{array}{l}\text { Default }(x) \\
\text { Performance }(1-x)\end{array}$ & $\begin{array}{c}\alpha R\left(1+\beta_{1}\right)-M, \alpha R\left(1+\beta_{2}\right)-M \\
\alpha R(\beta-r)+A, \alpha R\left(1+\beta_{2}\right)-M\end{array}$ & $\begin{array}{c}\alpha R\left(1+\beta_{1}\right)-M, \alpha R(\beta-r)+A \\
\alpha R(\beta-r)+A, \alpha R(\beta-r)+A\end{array}$ \\
\hline
\end{tabular}

TABLE 3: Evolutionary game steps.

\begin{tabular}{|c|c|}
\hline Steps & Rules \\
\hline$t=0$ & $\begin{array}{l}\text { A scale-free network } G_{1}(V, E) \text { and a small-world network } G_{2}(V, E) \text { with } N_{0} \text { nodes are generated. Then, the number of iterations } T \text { is } \\
\text { set, and the values of parameters } \alpha, R, \beta, \beta_{1}, \beta_{2}, M, A, r \text { are input. In addition, the two types of strategies are randomly assigned to } \\
\text { each node, and ensure that the number of nodes for each strategy is } 50 \% \text {. }\end{array}$ \\
\hline$t=1$ & $\begin{array}{l}\text { In the first game, the farmer node randomly selects the neighbor node for income comparison. If the income is less than that of the } \\
\text { neighbor node, the strategy will be changed according to formula (2). If the strategy is the same, the strategy will not be changed. }\end{array}$ \\
\hline $\begin{array}{l}t=2 \\
\text { It end }\end{array}$ & Is at $t=T \quad$ According to formula (3), the broken edges between nodes are reconnected. \\
\hline
\end{tabular}

means of production. After the order is completed, the farmer pays back the loan. The annual interest rate is between 6.5 and 12 percent, and the loan amount can be up to 5 million yuan $[46,47]$. Therefore, the interest rate is $10 \%$ $(r=0.1)$, and the account receivable line (order line) is 100,000 yuan $(R=10)$ in this paper.

3.4.2. Simulation Analysis. Since it is difficult to completely obtain the actual data, this paper makes reasonable assumptions regarding the parameter settings based on a practical case. Based on the available data, the parameters are selected as follows. The mortgage rate $\alpha=0.7$. The network size is 500 nodes. The number of iterations is 100 , and the initial default ratio is 0.5 .

Case 1. $M=4, A=4, \quad \beta=0.25, \quad \beta_{1}=0.1$, and $\beta_{2}=0.2,0.25,0.3,0.35,0.4$.

(1) When $\beta_{1}=0.1, \quad \beta_{2}=0.2,0.25$, there are $\alpha R\left(1+\beta_{1}\right)-M<\alpha R(\beta-r)+A$, $\alpha R\left(1+\beta_{2}\right)-M<\alpha R(\beta-r)+A$. At this time, the default income of all farmers is less than the performance income. As shown in Figure 1, in the small-world network, the default diffusion curve fluctuates continuously below 0.5. According to
Figure 2, the default diffusion curve in the scale-free network shows a trend of constant fluctuation.

(2) When $\beta_{1}=0.1, \quad \beta_{2}=0.3,0.35,0.4$, there are $\alpha R\left(1+\beta_{1}\right)-M<\alpha R(\beta-r)+A$, $\alpha R\left(1+\beta_{2}\right)-M>\alpha R(\beta-r)+A$. At this time, if farmers in Group 1 choose the default strategy, the income will be less than the performance income. However, when farmers in Group 2 choose to default, their income is greater than their performance income. As shown in Figure 1, in the small-world network, the default diffusion curve still fluctuates below 0.5 . As seen from Figure 2 , when $\beta_{2}=0.4$, the default diffusion curve in the scale-free network gradually tends to the stable state of 1 .

Conclusion 1: When the default return rate of farmers is small, and the returns of the default strategy are all less than the performance return, less than $50 \%$ of the farmers in the network will default. The default diffusion curve in the scalefree network fluctuates constantly. When some farmers in the network choose the default strategy gains more than the performance gains, in the small-world network, the default diffusion curve is still below 0.5 and fluctuates continuously. However, in the scale-free network, when the default yield 


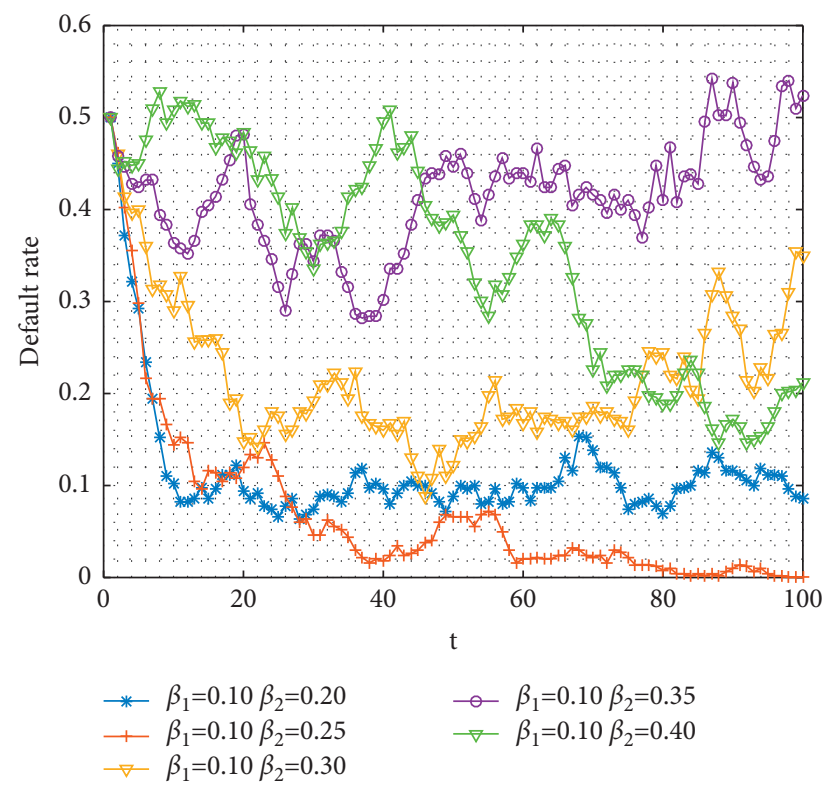

Figure 1: Diffusion of default behavior in a small-world network with the increase of $\beta_{2}\left(\beta_{1}<\beta\right)$.

breaks through a certain threshold, the default diffusion curve gradually tends to a stable state of 1 ; that is, all farmers choose to default.

Case 2. $M=4, A=4, \quad \beta_{1}=0.25, \quad \beta_{2}=0.3$, and $\beta=0,0.04,0.08,0.12,0.16,0.2$.

When $\beta<\beta_{1}, \beta_{2}$, and $\alpha R(\beta-r)+A<\alpha R\left(1+\beta_{1}\right)-M$, $\alpha R(\beta-r)+A<\alpha R\left(1+\beta_{2}\right)-M$. At this time, the default income of all farmers is greater than the performance income. Comparing Figures 3 and 4, when the performance rate is less than the default rate, the default diffusion curve in the small-world network tends to the stable state of 1 in a shorter time. That is, compared with the scale-free network, the default behavior in the small-world network spreads to the whole network faster.

Conclusion 2. When the performance rate of all farmers is less than the default rate, the small-world network is more conducive to the spread of default behavior. Therefore, when the market situation is bad or natural disasters occur, and the income of farmers' normal revenue cannot be guaranteed, the small-world network structure is more likely to promote the spread of farmers' default behavior throughout the network in a relatively short time.

Case 3. $A=4, \quad \beta=0.25, \quad \beta_{1}=0.35, \quad \beta_{2}=0.4$, and $M=0,2,4,6,8,10$.

When $\beta<\beta_{1}, \beta_{2}$, as seen from Figure 5 , in the smallworld network, the diffusion depth of default tends to a stable state of 1 as the punishment $M \leq 2$; that is, all farmers choose to default. When the punishment $M \geq 6$, the default diffusion curve tends to a stable state of 0 ; that is, all of the farmers choose to perform the contract.

In Figure 6, when the punishment $M \leq 2$, the diffusion depth of default behavior tends to a stable state of 1 . In addition, when the punishment $4 \leq M \leq 8$, the curve fluctuates. There is no equilibrium. Until $M$ increases to 10 , the default diffusion curve will approach 0 .

Conclusion 3. Increasing punishment can restrain the spread of default behavior to a certain extent. In addition, the small-world network is more sensitive to punishment than the scale-free network, and the effect is better.

Case 4. $M=4, \beta=0.25, \quad \beta_{1}=0.35, \quad \beta_{2}=0.4$, and $A=0,2,4,6,8,10$.

When $\beta<\beta_{1}, \beta_{2}$, as shown in Figure 7, in the small-world network, the diffusion depth of default tends to a stable state of 1 as $A \leq 4$. When $A \geq 6$, the default diffusion curve tends to a stable state of 0 .

In Figure 8, with the increase in additional benefits $A$, the default diffusion curve gradually changes from a stable state of 1 to a state of constant fluctuation and does not tend to 0 .

Conclusion 4. In the small-world network, the increase in additional benefits can restrain the spread of default to some extent. However, in the scale-free network, the increase in additional benefits has no obvious effect on the spread of default.

\section{Discussion}

The diffusion process of farmers' default behavior and the effects of various influencing factors are visually observed through network evolutionary game. In this research, the game relationship between farmers is characterized by evolutionary game theory. Then, the contagion process of farmers' default behavior is studied by combining with the complex network theory. In this case, farmers' active learning behavior is emphasized, which is different from previous studies. Moreover, the diffusion process of farmers' default behavior is studied in small-world and scale-free 


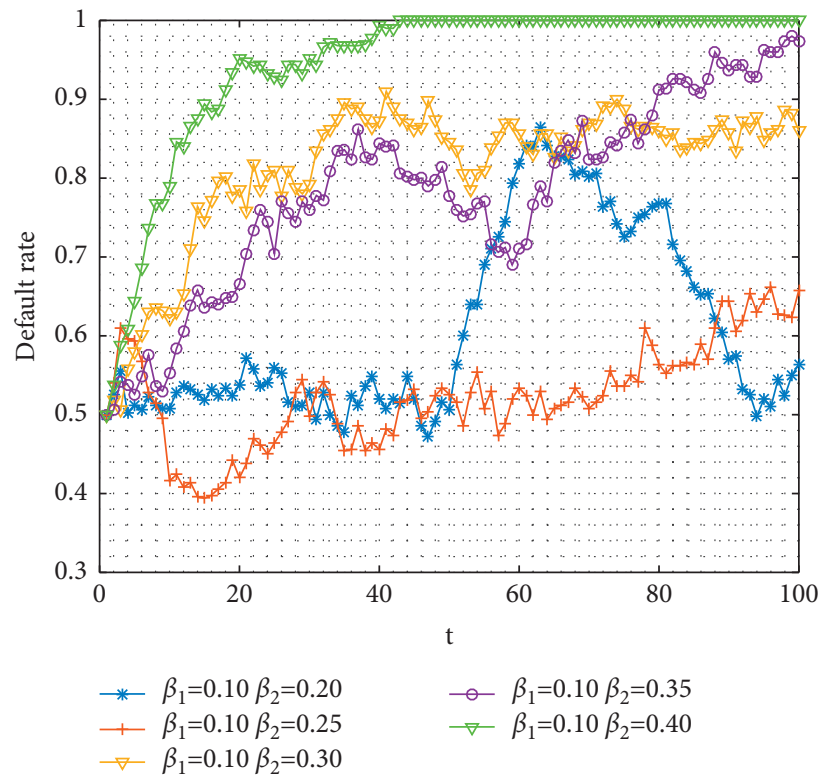

Figure 2: Diffusion of default behavior in a scale-free network with the increase of $\beta_{2}\left(\beta_{1}<\beta\right)$.

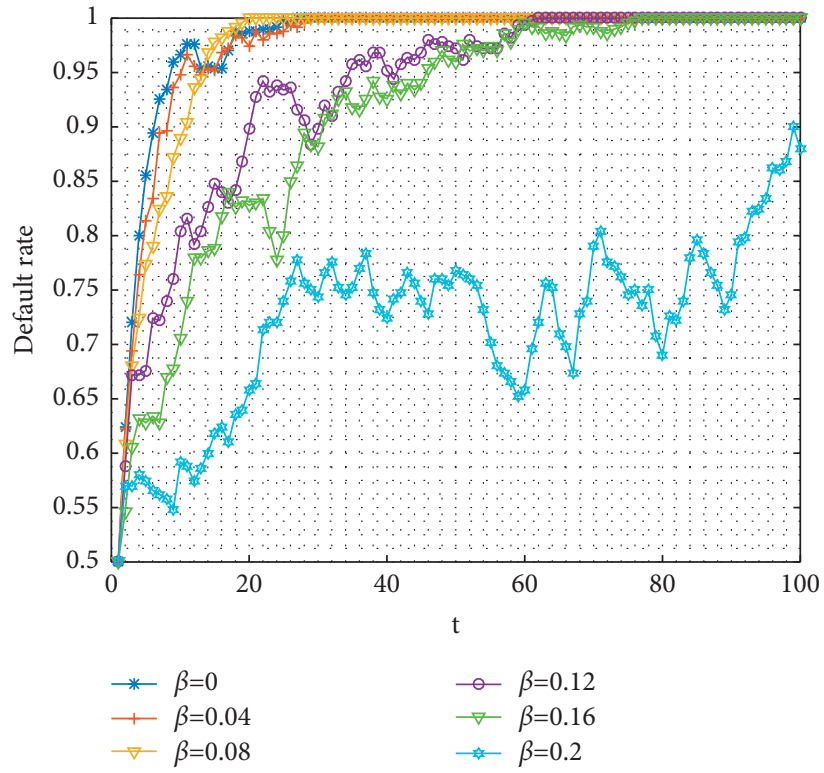

Figure 3: Diffusion of default behavior in a small-world network when $\beta<\beta_{1}, \beta_{2}$.

networks, respectively. It enriches the research perspective of this field.

The results show the network structure as an important factor that affects the spread of default behavior. This has been mentioned by other literatures $[[18,20,48,49]]$. Besides, it is found in this paper that the small-world network is more conducive to the spread of default behavior when the performance rate of all farmers is less than the default rate. But the small-world network is more sensitive to punishment than the scale-free network, and the effect is better. Meanwhile, results also show that the increase in additional benefits has no obvious effect on the spread of default in the scale-free network. But in the small-world network, the increase in additional benefits can restrain the spread of default to some extent. At last, in the small-world network, when the benefits of some farmers choosing the default strategy are greater than the performance benefits, the behavior of farmers who choose the default strategy will not drive all farmers to default. However, in the scale-free network, when the default yield exceeds a certain threshold, the driving effect is obvious; that is, all farmers in the network may choose to default. 


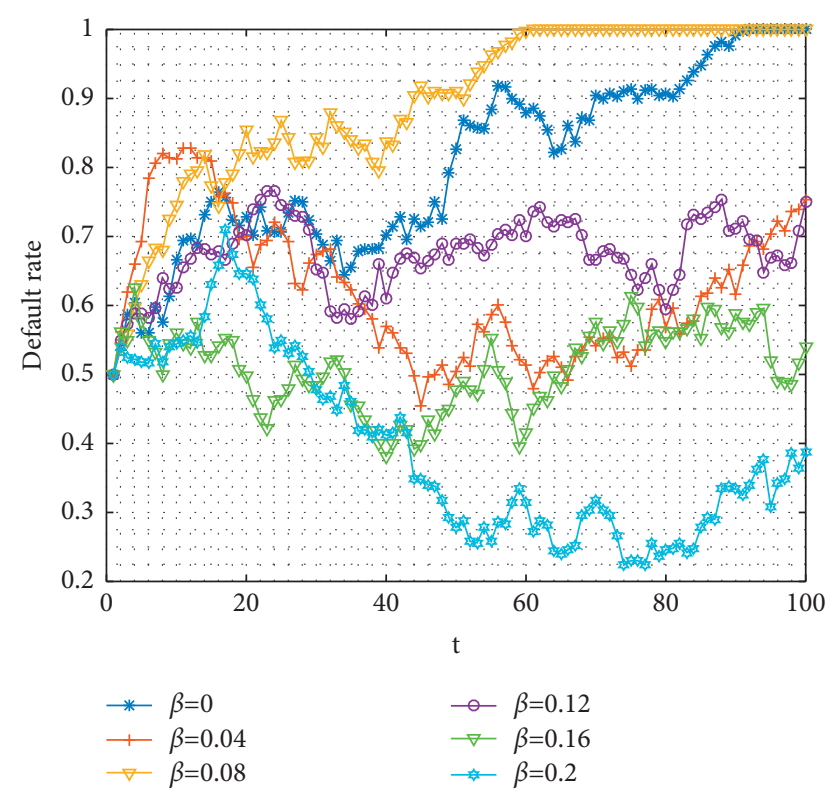

FIgURE 4: Diffusion of default behavior in a scale-free network when $\beta<\beta_{1}, \beta_{2}$.

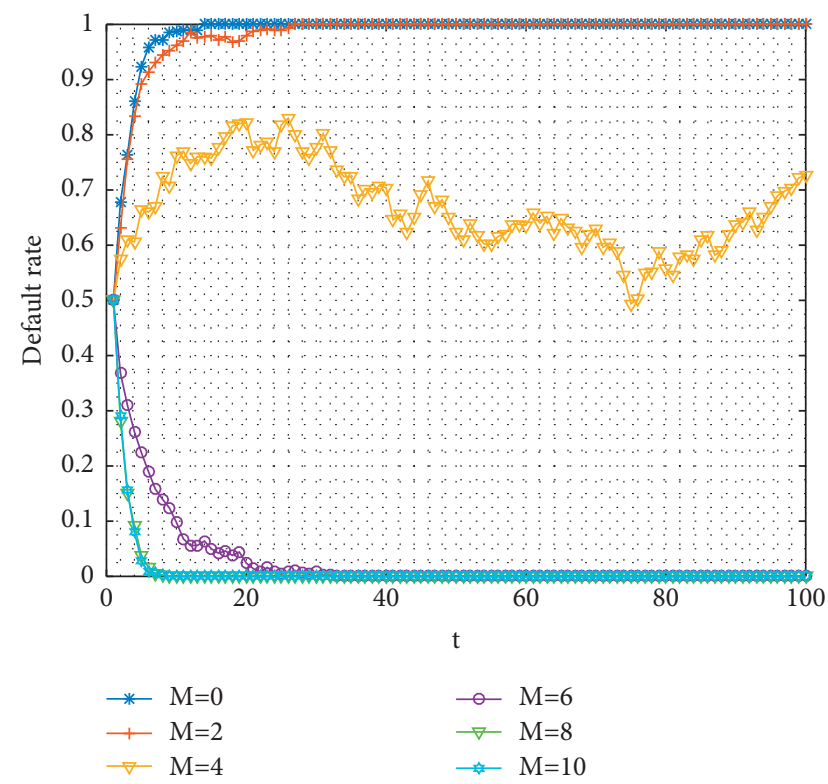

FIGURE 5: The effect of the punishment mechanism on the spread of default behavior in a small-world network.

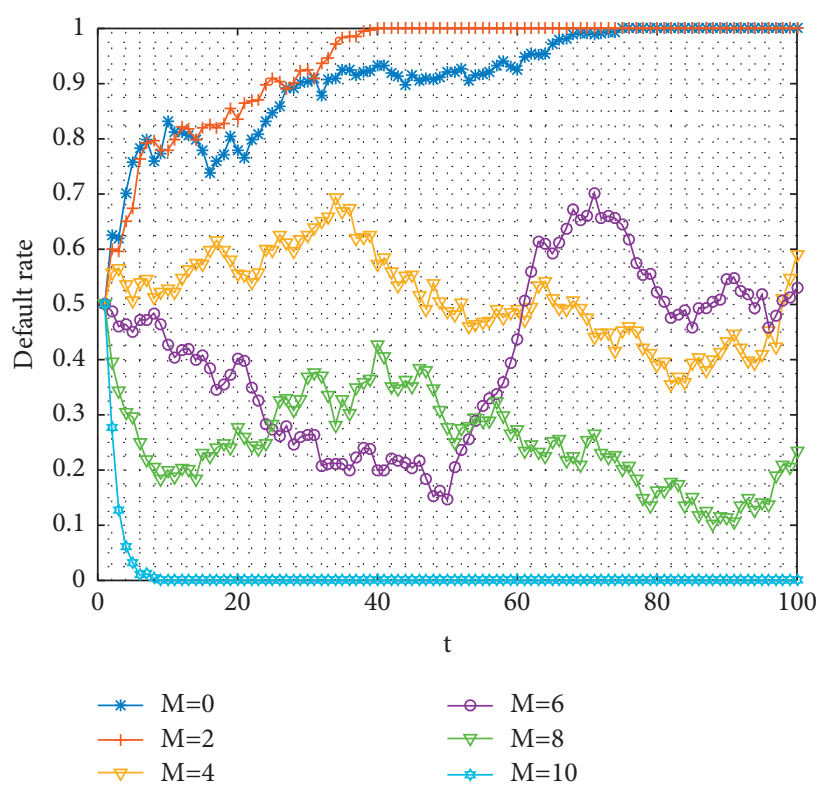

Figure 6: The effect of the punishment mechanism on the spread of default behavior in a scale-free network.

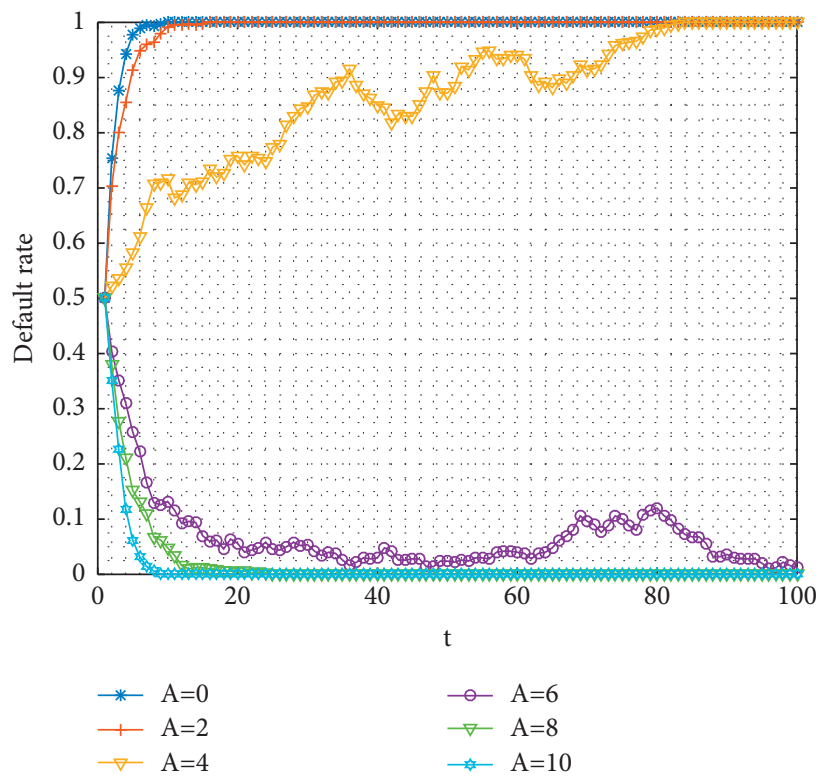

Figure 7: The effect of additional benefits on the spread of default behavior in s small-world network. 


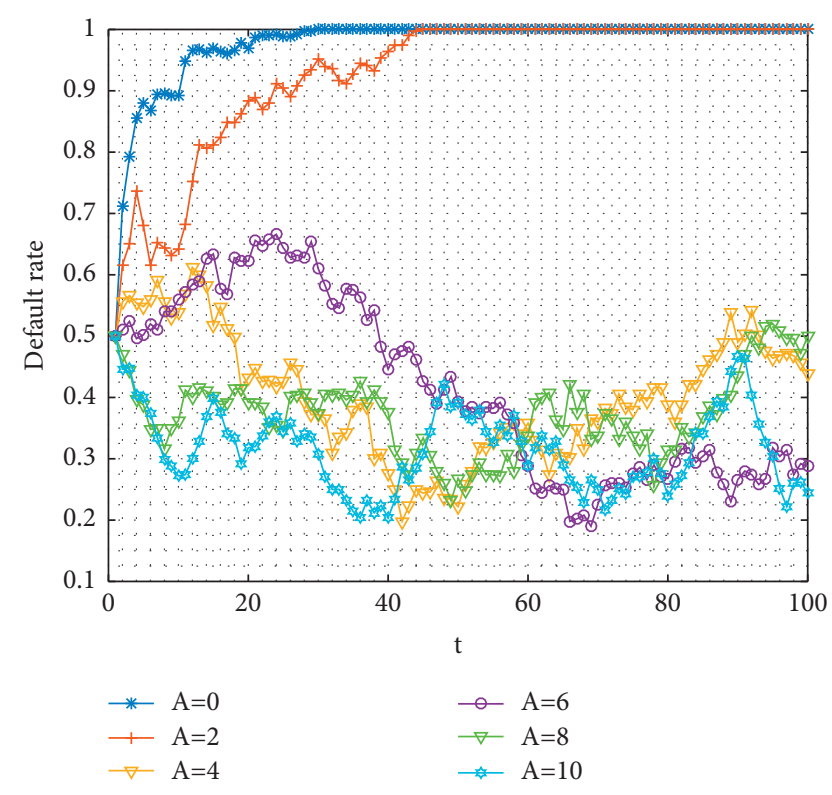

FIGURE 8: The effect of additional benefits on the spread of default behavior in s scale-free network.

\section{Conclusions and Future Research}

The diffusion of default behavior in supply chain finance has received increasing attention from both academics and practitioners. Based on a network evolutionary game, an evolutionary game model among farmers is constructed in this paper. According to the corresponding evolution rules, the influence of various factors under different network structures on the diffusion process of farmers' default behavior is explored through numerical simulation.

The results provide several insights into the diffusion process of farmers' default behavior in supply chain finance. First, when the income of farmers choosing the default strategy is greater than the income of performance, in a small-world network, less than $50 \%$ of farmers will choose to default, and the default behavior will not spread throughout the network. In the scale-free network, when the default yield breaks through a certain threshold, the default diffusion curve gradually tends to a stable state of 1 ; that is, all farmers choose to default. Therefore, in normal years, if there are borrowers with a certain influence among farmers, and they show the characteristics of a scale-free network, attention should be given to the supervision of speculative behaviors of such borrowers to avoid the spread of default behaviors throughout the network and the appearance of the herd effect. Second, when the yield rate of performance of all farmers is less than the yield rate of default, the small-world network is more conducive to the spread of default behavior. That is, when the market situation is bad or natural disasters occur, and the income of farmers' normal operation cannot be guaranteed, the small-world network structure is more likely to promote the spread of farmers' default behavior throughout the network in a relatively short time. At this time, the government should strengthen the purchase and subsidies of agricultural products. Core enterprises, banks and other borrowing institutions should also take corresponding measures to help farmers overcome difficulties to prevent the excessive spread of default behavior. Special attention should be given to the behavior management of farmers in the small-world network. Three, increasing the punishment can restrain the spread of default behavior to a certain extent. In addition, the small-world network is more sensitive to punishment than the scale-free network, and the effect is better. Finally, in the small-world network, the increase in additional benefits can restrain the spread of default to some extent. However, in the scale-free network, the increase in additional benefits has no obvious effect on the spread of default.

The limitations of this study and future directions can be summarized as follows: first, although punishment, network structure, and additional benefits are identified as critical factors influencing the spread of default, external factors (e.g., governmental regulation) have not been considered. A valuable direction for future research is suggested to explore the impact of government regulation on the diffusion of default. Second, all farmers are assumed to be homogeneous stakeholders in the network, and the heterogeneity of farmers should be taken into account in the future.

\section{Data Availability}

Data are available upon request to the corresponding author.

\section{Conflicts of Interest}

The authors declare no conflicts of interest.

\section{Acknowledgments}

This work was supported by Innovative Talents Project of Ordinary Universities of Guangdong Province (Grant no. KA190578813).

\section{References}

[1] Z. Yi, Y. Wang, and Y. Chen, "Financing an agricultural supply chain with a capital-constrained smallholder farmer in developing economies," Production and Operations Management, vol. 30, 2021.

[2] K. Wang, T. Jiang, H. M. Liu, and G. C. Liu, "The efficiency of rural financial institutions in China-based on the comparison between stock market listed rural commercial banks and village banks," Journal of Agrotechnical Economics, vol. 9, pp. 20-29, 2018.

[3] K. V. Gouri and V. Mahajan, "Different models of financing small farmers' agricultural value chains," India Studies in Business and Economics, pp. 33-53, 2017.

[4] L. Peng, "The main characteristics of the financial risk in agricultural supply chian and the basic principles of risk prevention," The Theory and Practice of Finance and Economics, vol. 36, no. 6, pp. 20-24, 2015.

[5] The paper.cn, "Affected by natural disasters and regional default events, the non-performing rate of Dalian agricultural commercial bank exceeded 8\%"," 2020, https://baijiahao. baidu.com/s?id=1633596404999391750. 
[6] M. Swain, D. Zimon, R. Singh, M. F. Hashmi, M. Rashid, and S. Hakak, "LoRa-LBO: an experimental analysis of LoRa link budget optimization in custom build IoT test bed for agriculture 4.0," Agronomy, vol. 11, pp. 2-24, 2021.

[7] Y. Liu, X. Ma, L. Shu, G. P. Hancke, and A. M. Abu-Mahfouz, "From industry 4.0 to agriculture 4.0: current status, enabling technologies, and research challenges," IEEE Transactions on Industrial Informatics, vol. 17, no. 6, pp. 4322-4334, 2021.

[8] A. Dcr, B. Rw, B. Mw, B. Ml, and B. Cac, "Agriculture 4.0: making it work for people, production, and the planet," Land Use Policy, vol. 100, 2021.

[9] A. Abid and S. Jie, "Impact of covid on agricultural food: a strengths, weaknesses, opportunities, and threats (swot) analysis," Food Frontiers, vol. 1, pp. 1-11, 2021.

[10] S. Yin, L. Bai, and R. Zhang, "Prevention schemes for future fresh agri-products (FAPs) supply chain: mathematical model and experience of guaranteeing the supply of FAPs during the COVID-19 pandemic," Journal of the Science of Food and Agriculture, vol. 101, no. 15, pp. 6368-6383, 2021.

[11] X. C. Zhang, "Research on security risks and prevention mechanisms of agri-food supply chain," Issues in Agricultural Economy, pp. 162-172, 2021.

[12] H. Song, "Supply chian finance: evolution from financial orientation and supply chain orientation to network ecological orientation and fintech orientation," $R$ \& $D$ Management, vol. 32, no. 4, pp. 1-2, 2020.

[13] H. Song and X. Yang, "Research of the effects of SMEs' eompetence and network embeddedness on supply chain finance performance," Chinese journal of management, vol. 15, no. 4, pp. 616-624, 2018.

[14] B. Yan, K. Luo, L. Liu, and F. Yang, "Supply chain finance: a three-party decision model with suppliers' guarantees for retailers," Managerial and Decision Economics, vol. 41, no. 7, pp. 1174-1194, 2020.

[15] N. Yan, C. Liu, Y. Liu, and B. Sun, "Effects of risk aversion and decision preference on equilibriums in supply chain finance incorporating bank credit with credit guarantee," Applied Stochastic Models in Business and Industry, vol. 33, no. 6, pp. 602-625, 2017.

[16] Z. Yi, Y. Wang, and Y. Chen, "Financing an agricultural supply chain with a capital-constrained smallholder farmer in developing economies," Production and Operations Management, vol. 30, no. 7, pp. 2102-2121, 2021.

[17] W. Jin and J. Luo, "Optimal inventory and insurance decisions for a supply chain financing system with downside risk control," Applied Stochastic Models in Business and Industry, vol. 33, no. 1, pp. 63-80, 2017.

[18] H. Song, X. Yang, and K. Yu, "How do supply chain network and SMEs' operational capabilities enhance working capital financing? An integrative signaling view," International Journal of Production Economics, vol. 220, pp. 1-16, 2020.

[19] H. Song and X. Yang, "How does supply chain finance help SMEs financing-perspective of supply chain network embeddedness," R \& D Management, vol. 30, no. 3, pp. 22-33, 2018.

[20] M. R. Fayyaz, M. R. Rasouli, and B. Amiri, "A data-driven and network-aware approach for credit risk prediction in supply chain finance," Industrial Management \& Data Systems, vol. 121 , no. 4 , pp. $785-808,2020$.

[21] C. Steven and D. Rogers, "Broadening the perspective of supply chain finance: the performance impacts of network power and cohesion," Journal of Purchasing and Supply Management, vol. 25, no. 2, pp. 134-145, 2019.
[22] L. Zhang, H. Hu, and Z. Dan, “A credit risk assessment model based on SVM for small and medium enterprises in supply chain finance," Financial Innovation, vol. 1, no. 1, pp. 1-14, 2015.

[23] X. Wu and H. Liao, "Utility-based hybrid fuzzy axiomatic design and its application in supply chain finance decision making with credit risk assessments," Computers in Industry, vol. 114, pp. 1-19, 2017.

[24] Y. Zhu, C. Xie, G. J. Wang, and X. Yan, "Predicting China's SME credit risk in supply chain finance based on machine learning methods," Entropy, vol. 18, no. 5, pp. 1-8, 2016.

[25] Y. Zhu, C. Xie, G. J. Wang, and X. Yan, "Comparison of individual, ensemble and integrated ensemble machine learning methods to predict China's SME credit risk in supply chain finance," Neural Computing \& Applications, vol. 28, pp. 41-50, 2017.

[26] Y. Zhu, L. Zhou, C. Xie, and G. Wang, "Forecasting SMEs' credit risk in supply chain finance with an enhanced hybrid ensemble machine learning approach," International Journal of Production Economics, vol. 211, pp. 22-33, 2019.

[27] X. Lyu and J. Zhao, "Compressed sensing and its applications in risk assessment for Internet supply chain finance under big data," IEEE Access, vol. 7, no. 99, pp. 53182-53187, 2019.

[28] X. Cai, Y. Qian, Q. Bai, and W. Liu, "Exploration on the financing risks of enterprise supply chain using Back Propagation neural network," Journal of Computational and Applied Mathematics, vol. 367, 2019.

[29] X. Liu, X. Peng, and M. Stuart, "Research on risk measurement of supply chain finance based on fractal theory," Fractals, vol. 28, no. 8, pp. 1-13, 2019.

[30] Y. Liu and L. Huang, "Supply chain finance credit risk assessment using support vector machine based ensemble improved with noise elimination," International Journal of Distributed Sensor Networks, vol. 16, pp. 1-10, 2020.

[31] Y. Liu and H. Yan, "A credit risk evaluation on supply chain financing for farmers' cooperatives," Journal of Nonlinear and Convex Analysis, vol. 21, no. 8, pp. 1813-1828, 2020.

[32] C. Wang, F. Y. Yu, and Z. X. Zhang, "Multiview graph learning for small- and medium-sized enterprises' credit risk assessment in supply chain finance," Complexity, vol. 2021, Article ID 6670873, 13 pages, 2021.

[33] Y. Wu, X. Li, Q. Liu, and G. Tong, "The analysis of credit risks in agricultural supply chain finance assessment model based on genetic algorithm and backpropagation neural network," Computational Economics, pp. 1-24, 2021.

[34] Y. Yang, X. Chu, R. Pang, F. Liu, and P. Yang, "Identifying and predicting the credit risk of small and medium-sized enterprises in sustainable supply chain finance: evidence from China," Sustainability, vol. 13, no. 10, pp. 1-19, 2021.

[35] H. Ying, L. Chen, and X. Zhao, "Application of text mining in identifying the factors of supply chain financing risk management," Industrial Management \& Data Systems, vol. 121, no. 2, pp. 498-518, 2020.

[36] L. Peng, "On the amplifying effect of financial moral hazard in the agricultural supply chain," Journal of financial reseach, vol. 4, pp. 88-103, 2018.

[37] X. S. Jin, W. Y. Yuan, J. Wu, J. Li, and Y. Wang, "Risk control of supply chain finance based on revenuesharing-bidirectional option contract," Chinese Journal of Management Science, vol. 128, no. 1, pp. 1-81, 2020.

[38] F. S. Zhang, C. D. Li, and C. J. Cao, "Mechanism of user participation in co-creation community: a network evolutionary game method," Complexity, vol. 2021, Article ID 6660568, 24 pages, 2021. 
[39] R. C. Basole and M. A. Bellamy, "Supply network structure, visibility, and risk diffusion: a computational approach," Decision Sciences, vol. 45, no. 4, pp. 753-789, 2014.

[40] H. Wang, T. Gu, M. Jin, and G. Wang, "The complexity measurement and evolution analysis of supply chain network under disruption risks," Chaos, Solitons \& Fractals, vol. 116, pp. 72-78, 2018.

[41] J. Wang, H. Zhou, and X. Jin, "Risk transmission in complex supply chain network with multi-drivers - science direct," Chaos, Solitons \& Fractals, vol. 14316, pp. 1-28, 2021.

[42] Q. H. Yang, C. M. Scoglio, and D. M. Gruenbacher, "Robustness of supply chain networks against underload cascading failures," Physica A: Statistical Mechanics and its Applications, vol. 563, pp. 1-16, 2021.

[43] Z. Zhao, D. Chen, L. Wang, and C. Han, "Credit risk diffusion in supply chain finance: a complex networks perspective," Sustainability, vol. 10, no. 12, pp. 1-20, 2018.

[44] Y. L. Wu, "The chaining linkage and networks of agricultural clusters," Journal of Henan University, vol. 50, no. 4, pp. 81-86, 2010.

[45] X. F. Wang, X. Li, and G. R. Chen, Network Science: An Introduction", Higher Education Press, Beijing, China, 2012.

[46] CS. Com, "Jingdong released the rural financial strategy--"Jingnongdai" open the road," http://www.cs.com.cn/sylm/ jsbd/201509/t20150920_4802589.html, 2015-09-20.

[47] CSAI, "Jingnongdai of Jingdong," https://www.csai.cn/loan/ 5500038.html, 2019-01-31.

[48] R. C. Basole, M. A. Bellamy, H. Park, and J. Putrevu, "Computational analysis and visualization of global supply network risks," IEEE Transactions on Industrial Informatics, vol. 12, no. 3, pp. 1206-1213, 2016.

[49] E. Letizia and F. Lillo, "Corporate payments networks and credit risk rating," EPJ Data Science, vol. 8, no. 1, pp. 1-21, 2019. 